\title{
Antonymic Opposition as a Reflection of the Universal and National Linguistic Picture of the World (On the Material of Kazakh Language)
}

\author{
I.S.Sultaniyazova ${ }^{1}$
}

\author{
A.K.Zhumabekova² \\ 1 PhD Doctoral candidate, Kazakh National Pedagogical University named after Abai \\ 2 Doctor of Philology, Professor, Kazakh National Pedagogical University named after Abai
}

\section{Doi:10.5901/mjss.2015.v6n4s2p448}

\section{Abstract}

This article defines universal and national directions of oppositional cognition. If we consider that life itself consists of opposites, it is understandable why researchers search for the picture of the universe in oppositions. In the article we discuss universal notion that is common to the whole humanity as well as each nation's own picture of the world appropriate to their culture and cognition. For the first time we prove that linguistic that linguistic units with opposite meanings is a tool that helps to convey common and national picture of the universe on the basis of materials in Kazakh language.

Keywords: opposition, universal picture, contrast, antonym, national cognition;

\section{Introduction}

Picture of the world in human's cognition is the complex of his personal life experience and contrasting features in his notion. Contrasts forms from the results of cognition of the world, creation, things and events in life.

Enormous contribution to the theory of antonomy were made by A.I.Alehina, Y.D.Apresyan, N.B.Boyeva, L.A.VVedenskaya, V.A.Ivanova, V.N.Kommisarov, I.L.Medvedeva, E.N.Miller, V.A.Mikhailov, M.V.Nikitin, L.A.Novikov, E.I.Rodicheva, N.L.Sokolova, M.M.Halikov, D.A.Cruse, S.Jones, J.S.Justeson, S.M.Katz, G.Leech, J.Lyons, A.Mettinger and etc.

Y.O.Novikova states that speech antonomy is a reflection of ordinary picture of the world which is interpreted as "integral reflection of the world on the level on the level of common sense. Ordinary picture of the world comes from life principles, which are accepted by subjects as self-obvious truth. Ordinary picture of the world is created by human's needs to comprehend and use centuries-old experience, gained by generations and reflects in his speech activities. Often researches use the term "naïve picture of the world" (Novikova 2010).

According to the results of cultural and linguistic researches we can assume that the original forms of thinking are binary structures that are expressed in language in form of semantic oppositions. In turn, they reflect substantial for human contrasting sides of events from national and social world around him.

Researchers involved in the reconstruction of picture of the world of various ethnos use "set of basic semantic opposition that have practically cross functional nature for people of the world" (Anikina 1988). This way of description of picture of the world was not chosen accidentally. Significance of binary oppositions is very high for any culture, because they reflects fundamental categories of existence (space, time, number, evaluation categories) and reveals its internal contraries. These categories are universal: they are inherent to human in all stages of historical development and they become basis of special model of world unique to each culture (Anikina 1988).

Reconstructing model of the world with the help of linguistic tools, researchers of ancient texts advanced a suggestion that this model presents a set of basic oppositions that have practically universal character for all human societies. For example V.V.Ivanov and V.N.Toporov, recreating model of Slavic world suggested semanticals oppositions such as: 'happiness-unhappiness', 'right-left', 'up-down', 'day-night', 'friend-foe' and etc. Authors came to the conclusion that such oppositions, independently reconstructed for pro-Slavic language, essentially coincide with oppositions of Finno-Ugric and some Turkic languages (Ivanov and Toporov 1965).

To the text, which reflects the traditional spiritual and material culture of the peoples, paremias can be included. They can be considered as fixed in the language consciousness stereotypes of the ethnic group associated with different forms of communication. A fundamental study of the structure of paremias that reflect the process of learning about the 
world by people in far away times, undertaken by G.L.Permyakov showed that genuine theme of any proverbs or sayings is some invariant pair of opposing entities, to which the meaning of images used in the paremias are reduced (Permyakov 1988). As a criterion for classifying a large folklore material of different nations of the world the author put forward schematic types of such invariant pairs that let to eliminate the disadvantages of the existing collections of paremias based on alphabetical, lexical, thematic and other principles. A common feature of uniting paremias in one group or another is the type of opposition between the components of semantic oppositions.

Sharing the view G.L.Permyakov that each proverb or saying contains a hidden or overt opposition, we have chosen the object of study only those paremias that contain actualized antonymous pairs.

For the analysis, we selected 426 Kazakh proverbs and sayings drawn from the collections paremias (Akkozin 1990), and 290 sentences with antonymous oppositions extracted from modern fiction.

\section{Literature Review}

\subsection{Universal and national antonymous oppositions}

Antonymic opposition, on which paremias are based, versatile for different languages, as based on unified laws common to all mankind thinking. The differences are expressed in lexemes, which reflect the specific features of national life, economic structure, due to historical, geographical, cultural and other factors, affected the course of development and formation of the ethnic group.

Thus, universal for all languages opposition Friend or Foe implemented in the Kazakh paremias:

'Kisi elinde Sultan bolgansha, oz elinde ultan bol'

(lit .: Than being the Sultan in a foreign country, it is better to be the sole at home);

Here to the main usual opposition they added additional contextual: sultan - ultan. The latest reflects the realities (sultan - ultan) that are specific for the life of the Kazakh people in the recent past. In generalized form, the opposition sultan - ultan manifest a couple of usual better-worse and relate to the main antonymic pair friend-foe.

"Excessive selfish cruelty is when person does appreciate neither others, nor himself" (Zhumadilov 2003).

The thing that warmed his heart about his neighbours was that they were talking not in foreign language but in their mother tongue (Batyr 2008). These examples show that opposition friend-foe has its own place in literature.

Oppositions in the paremias are often based on observations of the realities of life, on understanding the single entities of opposite phenomena:

'Stallion is sometimes nourished and sometimes not,

A man sometimes has money and sometimes not'

Frequent parallels with the life of animals and humans in the Kazakh proverbs and sayings are based on the awareness of the unity of Nature and Human. This attitude evolved over many centuries of life of the Kazakh people, 'immersed' in nature.

Among the proverbs containing gradual opposition, we can distinguish a subgroup of antonymous pairs in which the relationships between the components are characterized by semantic asymmetry. One of the oppositions has additional connotations, which strengthen or weaken the value of the symmetric antonym, such as 'wealth-poorness', 'many-loneliness':

"Do not boast about wealth,

When there is poor.

Do not boast about being among many,

When there is loneliness".

In this proverb, as we think, the essence of such method as the intentional use of asymmetric antonyms is expressed. Counter-term of any feature may be characterized not just with reducing the quality, but also with its minimal decrease. Thus, the reverse side of wealth /'baylyk'/ can be not only poverty /'kedeylik'/, but also poorness /'zharlylyk'/, as well as large number of close relatives /'koptik'/ can turn not only into decreasing of their number, but also to complete Ioneliness /'zhalgyzdyk'/. Therefore, the proverb teaches, do not boast what you have now /'maktanba'/ since you can lose everything later. 
For example: "Will a poor man, who does not own even a scrag, wake up one day with paddock full of sheep and horses?" (Akpanbet 1994).

"Even a rich man with thousands of cattle, and a poor man with skinny horse, a hapless destitute or aristocrat with more gold than one can count survive as they can and meet their fate"(Bakbergenov 2000).

From these examples we see that gradual members of semantic asymmetry have feature to be able to move in opposite direction in traditional increase-decrease scale. Due to the fact that livestock raising was main occupation of Kazakh people, wealth was measured by how much stock does someone own.

One pole of asymmetric scale can be represented by zero quality, and the other one be open and able to increase, for example, in paremia 'Silent wins over the chatterbox' states that silence is better than inappropriate verbosity.

Asymmetry in proverbs can be expressed on the grammatical level of actualization by inter-part of speech antonymy:

\author{
'What's the use of wide world if your own shoes are tightly fitting"; \\ 'Seam clothes loose, \\ It's easy to make it fit. \\ Cut iron short, \\ It's easy to lengthen it' \\ There are lots of oppositions for every part of speech from literature: \\ "His peace of mind was contaminated, like the water to which a stone was thrown"(Zhumadilov 2004). \\ "Depending on the results of his work, he either glows with happiness or grimmer than a storm cloud" (Zhumadilov \\ 2003). \\ "I could find anything light in this brawler's heart, it's completely dark" (Zhumadilov 2003). In this sentence opposition \\ pair 'bright and dark' used figuratively, so they are contextual antonyms.
}

\title{
2.2 Contextual antonyms as a tool of creating universal image in national cognition
}

In Kazakh paremias there is a large amount of contextual antonymous pairs. This is explained, apparently, by the fact that in the tradition of Kazakh oral poetry improvisation has a main role. The ability to speak and sing in poetic form has always been recognized as the basis of rhetoric. This method of transmitting thoughts perceived as bright, unusually strong artistic means of impacting the audience, which, in turn, easily memorized rhyming lines. Thus, the creation of opposition was motivated not only by logical, but also by linguistic reasons.

The similarity of the sound form of the word united them in pairs: 'kop-dop'(many-pithily: 'Kop soylegen bilimdi emes, dop soylegen bilimdi' - 'Clever not who speaks many, but those who speak pithily'), 'tor-kor' (honorable place grave: 'Dostyn orny - tor, dushpannyn orny - kor' - 'Friend's place is honorable place, enemy's place at grave'), kozi-ozi (eyes-himself: 'Bireudin kozi sokyr, bireudin ozi sokyr'- 'One has coward eyes, the other is coward himself').

Such kinds of contextual antonyms were masterfully used by authors of following examples:

"He seemed to me as rude, unstable, weasel person, who depending on his mood, could be either cheerful as child, or grumpy as an old man" (Bakbergenov 2000).

"It's a time when ones are fresh, and others are shabby" (Zhumadilov 2004).

"Autumn's days are sometimes harsh and sometimes cozy" (Akpanbet 1994).

Here each contextual opposition can be qualified as a manifestation of a certain type of usual. In Kazakh proverbs they can be easily seen occupying similar positions in the parallel syntactic structures:

'One may have heavy stick,

And the other has crushing words'

Let's take a famous proverb 'If father have good son, he will drag him from threshold to honorable place. If father has bad son, he will drag him from honorable place to the threshold'. Here we want to pay close attention to the symbol of honorable place (tor) in national understanding. 'Honorable place' and 'threshold' as opposites shows dynamic development by model up-down, by age it shows the path of life, the model by which youngsters sit near the door and elders sit further. However in the article above, 'honorable place' is a symbol of respect and 'threshold' is a symbol of losing that respect and honor.

Contextual oppositions can be used in one text in one way, but have another meaning in other texts: 
"Syrym could not understand how someone could have such beauty and tenderness along with such cruelty and hardheartedness" (Zhumadilov 2004).

"The house may be crowded, but mind is spacious, we will fit in"(Zhumadilov 2003).

To contextual pair we include: 'silk-wool', 'soft-hard', 'silver-gold', 'coal-gold', 'cheap-expensive', 'many-little' and etc.

'Few words are gold, many words are coal.

The one, who can't handle silk, will make it wool,

The one, who can't handle daughter-in-law, will make her slave'.

Good and bad, wise and hapless, they all have one dream: to create a happy family and have children (Batyr 2008). In this example, words wise and hapless are contextual antonyms that used with the meaning clever and fool.

Specific images of things and animals have generalizing value in proverbs. Thus, in the proverb:

'You may steal camel or button, you are thief in any case' contextual antonyms 'camel-button' also represent gradual pair 'big-little', 'expensive-cheap'. And the didactic significance of it is that the theft can not be justified by sizes or value of things.

"An old woman may have shaban walk but her words are nimble" (Zhumadilov 2003). Kazakh people use word 'shaban' ('sluggish') referring to walk of animal, and here it used figuratively. However, any Kazakh that knows horse's sluggish walk will immediately understand the metaphor in proverb and slowness of old woman's walk.

A shepherd's place is empty two seasons in a year, because in summer he pastures at zhailau, and at kystau in winter (Batyr 2008). Due to the width of land, Kazakh people tend to graze cattle in one place(kystau) in winter, and change it in summer to place where grass grows thick (zhailau).

It doesn't matter whether we're lamb or wolf-cub, if we were not inured (Bakbergenov 2000). For Kazakh people, who are very familiar with livestock, lamb is a baby of meek animal sheep, wolf-cup is an offspring of wild wolf that attacks livestock and kills it.

Contextual opposition often used with common usage:

He started his live in boundless steppe, but going to die in a small cage (Zhumadilov 2004).

\subsection{Appearance of universal and national linguistic image of the universe through concepts}

Intermediate position between common usage and contextual occupied by such opposition, in which one component of usual antonymic pair contrasted words in the lexical-semantic after the second antonym, for example: 'evil humaneness' /'evil - good'/, 'to get old - to get stronger' /'to get old - to get young'/.

'I am thankful for all good and bad days that I have lived through' (Akhmetzhan 2008). If in this sentence good and bad are usual opposition, following sentence is an example of intermediate opposition:

'You can expect from life not only good things but also a danger!' (Zhumadilov 2004).

In words with contrast meanings lies the people's worldview. We can prove that lexemes good/evil as pair is used very often with next examples:

'The most difficult time for human when either good or evil grabs you by the throat.

Anything bad has its own good side.

If we think about it, there is neither evil nor good without actual owner' (Zhumadilov 2003).

Elders may say 'If you extend a helping hand to person in his difficult times, or harm and disserve him, you will not get away with it. One day you will answer for it' (Akanbet 1994). While soul, heart, beauty, right side, bright sunray, white color are used as symbol as goodness, callousness, ugliness, left side, darkness and black color are used as opposite and represent evilness.

"Concept of good/evil is universal category in each ethnical culture, and at the same time, it has national features that can be observed in conceptual and other components"(Shalbayeva 2010).

Among Kazakh people respect, appreciation and admiration for parents is considered as goodness. It shows 
heartiness, kindness and respect for elders in people's worldview. Phrases like 'kind word', 'good thoughts', 'good wish', 'sincere intentions' that share the meaning of good are frequent in Kazakh language, which certainly shows that people pay special attention to words and understand their power. And evilness is used with words such as: lying, tricking someone, sadness, sorrow, bad words, death and betrayal in equal level.

B.K.Akberdieva claims that people after dividing the world around by the principle of good and evil, helpful and harmful search for the link between them, and names the trio white - black-n-white - black as the main icon of the world. She states: "Black-n-white has an important role in many national cultures as the symbol of the existence, creation on the surface of the planet" (Akberdieva 2000).

White color is the upper world, mansion of gods, symbol of pureness and innocence;

Black-n-white is the Earth, mediator between two utmost worlds, it's an existence that absorbed nature and features of white and black, of upper and underworld; it's a commotion;

Black color is underworld, abyss, centre of depravity, death.

Pair white-black is gradual opposition, because black-n-white is its intermediate.

Systematic usage of colors 'white' and 'black' as oppositions is a special phenomenon that peculiar only to them. In literature they are constantly being used as oppositions:

'Now you can not draw a picture using only white and black.

White sheet of paper is your conscience, black ink is your blood' (Zhumadilov 2004).

U.B. Serikbayeva shares her opinion: "This phenomenon is a pair concept that was created in particular logical system. It's a factor that has crucial part in uncovering secrets of events which were always perceived as mottled in natural and social life and described as contrast and opposite"(Serikbayeva 2005). According to U.B. Serikbayeva human's perception of the world are connected with these colors from the early beginning. She states that: "these colors are the most suitable for dividing and allocating things and events in the world and act as catalyst for other colors" and equals colors 'black' and 'white' to the symbols of night and day (Serikbayeva 2005).

Most of additional (cognitive) meanings that are attached to 'white' and 'black' can be met in one language, but be absent in other language or does not be appropriate. In Kazakh language 'white' (ak) can mean dairy produce both separately and within the text. Color 'white' used as opposite to color 'black' in almost all Turkic languages. In Kazakh language there are hundreds of phraseologisms and proverbs where white is used with nominative meaning. Among researchers who wrote about relation of 'white' to the life of ethnos, their traditions and worldview, we want to name A.Kaidar, Z.Aktamberdieva, B.Omirbekov, F.Akhmetzhanova. K.Kaiyrbayeva. If earlier A.Kaidar, Z.Aktamberdieva and B.Omirbekov studied color 'black' and pointed its 24 types, U.Serikbayeva named 33 types of its figurative meaning and determined its cognitive meanings.

One of its cognitive meanings is dish that prepares without fat and clabber. In centuries-old traditions and customs of nomad Kazakhs main dishes were made from milk, butter, meat, 'kymyz', 'kymyran' and 'shubat'. We can notice that all food could be divided into two large groups, where fatty foods were compared to white and yellow colors and non-fatty foods were compared to black color. From this black adopted figurative meaning for all non-fatty foods without milk. As prove we can name such phrases as: 'kara kesek et' (lit. 'black meat', meat without fat), 'kara talkan' ('black oatmeal'), 'ak mai' ('white butter'). Also 'white' and 'black' denotes areas where Kazakh tribes used to live, "often place where sun arises is bright and light and marked as 'white', whereas place of sunset becomes darker and marked with 'black'" (14). In addition, there is belief that 'black' has subtext of lie, accuser, slanderer and guilt. Indeed, there is a reason to attachment of white to blessings and gratitude. In our tradition white blessings has the meaning of satisfaction and good intentions, while 'black' ones mean offense and badness. It can be observed in the following examples:

'Anyway define whites and blacks of the case' (Batyr 2008).

'And if you started to doubt, soon you are going to turn white to black, and black to white' (Akhmetbekov 2010).

The one is 'aktaushy' (vindicator; lit. 'person who make it white') and the other is 'karalaushy' (accuser; lit. 'person who make it black') (Zhumadilov 2004).

As we noticed in examples, white is indisputable symbol of purity and innocence. Furthermore, there is a opposite phrases such as 'ak bet'and 'kara bet' (lit. 'white face and black face'). If 'white face' means that person has not guilt or fault, 'black face' refers to someone who committed a crime or did something shameful. In earlier times person who committed a crime or did very shameful things was painted his face with black soot, sat backwards on black cow or donkey and leaded by black leash on his neck. And people used to spit on him, saying 'black face'. This phrase is come 
from that custom.

Kazakhs refers with color black to creatures of black forces, such as: jinn, 'shaitan' or 'albasty', that's why white, as opposite referred to ghosts and angels.

From works of S. Kanapina we can observe that by colors people demonstrate their own aesthetic point of view, emotional state and concepts of humaneness: "As for any other nation, for Kazakhs world divided into two colors: black and white. While white is an image of everything good and decent, in many cases black posses everything bad and evil" (Kanapina 2006).

'White' is a gratitude, 'Black' is a curse.

The truth will divide black and white.

Kydyr ata's image perceived as an old man with snow-white beard, white turban and white chopon. White shawl is a symbol of young woman, wife. As for black color, there is phraseologisms as black veil, black paper, black horse (horse of dead man), black voice (mourning), black day (day of mourning). The opposite concept of 'ak otau' (white housing) is 'karaly ui' (lit. black house; mourning house). In ancient times, if man of middle age died, his home was tied with black clothing and his wife wore black. Still the house, where someone died called 'black house'. There is also lies a national notion in calling letter with notification about death of soldier in time Great Patriotic War as 'black paper'. Also, white and black houses is the indicator of people's wealth. Wealthy men lived in yurt made from white felt, whereas poor people lived in black felted yurts. Words 'aksuiek-karasuiek' (lit.white-boned, black-boned) are also have opposite meanings and means rich people and poor people.

If meaning of the life is in recognizing the unity and struggle of opposites, that concept, in Kazakh people mind, is set around white and black. Therefore white color that symbolizes joy, happiness and goodness is set as the opposite of black, which in its turn, is the symbol of distress and evilness.

Invariant gradual opposition can be expressed and by contrasted comparative constructions too:

'Taudai sozdin tarydai tuini bar' (lit. 'Mountain-like amount of words has millet-like point'; antonymic pair/many-little).

Here we see concept of volume. Mullet is small by size and little by volume. It compared to mountain that is big by volume. For Kazakhs, mullet is the symbol of source of life and satiety. Concept of 'mullet' participates in structural unit in building concepts such as: mastery, beauty, growth, prosperity and etc. which have high social meaning.

You enter as mullet,

And leave as mountain - this excerpt from poem can be used referring to concept of 'growing up', because it describes how children who are like 'mullet' grow up 'as mountain'.

Examples cited above indicate that not only the common usage, but also contextual oppositions manifest abstract pairs of contrasting entities.

In Kazakh language there are hundreds of types of concepts that refer to the phenomena based on oppositions in life.

Concepts based on oppositions in life in Kazakh linguistics were object of research of S.A.Zhirenov, Zh.T.Koshanova, and A.Z.Shalbayeva. S.A.Zhirenov in his research defined cognitive nature of concept 'life-death' taking poetry of poets and bards as the basis.

S.A.Zhirenov takes concept as lingo-cognitive notion unit, and concludes that 'life-death' is a special 'dominant with conceptual meaning' appropriate to ethnos' own mentality (Zhirenov 2007). He states that human perceive the world partially, because perception of conceptual nature of life directly and all at once can be harmful for human's cognitive mechanism.

Integral components of meaning of macro-concept of 'life' consist from frame chain of micro-concepts such as: the world, time, era, fate, existence and etc. It has logical models as: Life is time, Life is school, Life is interesting, Life is light, Life is fight, Life is precious, Life is traitor and etc. and it's components is linguistic models. It's a binaural pair 'Soul and body': intermediate concept that covers national-cultural concept 'Life and Death'. There is a rationale of the image of 'soul and body' which is ethnos' way of thinking. Macro-concept 'death' is lingo-philosophical unit common to whole humanity, which has structural units like demise, doom, decease. For example:

'Why do I need secrets when I'm in flame of life and death.

And yet, I think soldier's heart, who is always between life and death, becomes merciless.

'It glorifies the struggle between life and death, and the warrior's courage' (Bakbergenov 2000).

'How Daryn exactly knew the man's internal struggle between life and death' (Akmetzhan 2007). 
Life-death concept can be conveyed by integral units with similar meaning. Like this, pair 'to live and to die' can be intended with other words in the literature:

'It's like a man lived his life as mottled, sparkled, and had a similarly ceremoniously rest after he closed his eyes forever' (Zhumadilov 2003).

'Of course, it's not new to live and to die in this world' (Zhumadilov 2004).

'I came to this world as thirsty for freedom, and leaving it as equally thirsty' (Akhmetzhan 2007).

'What can be better for human to make his last breath because of natural cause, rather than from any other cause, since he comes to this world naturally' (Batyr 2008).

In these examples phrases: close eyes forever, leave the world, last breath indisputably mean the death. While, come to world means to be born.

'He put the old man, whose first-born came to this world in the morning in the right side of the house' (Naimanbayev 1991).

To be born and to die are equipollent oppositions, because these are actions with contrasting directions. In the example author use the action of being born to as the opposition to death. By Kazakh tradition dead people were put at the right side of the house, so reader immediately understands that old man has died, and it's clear that some events happened.

Elders used to say "man in a shroud will not come back, but man in kebenek will" and this is quite true...( Kaupynbayev 1986) In Kazakh traditions dead man is dressed in a shroud, so in this example 'man in a shroud' means that dead people will not come back. 'Kebenek' is a type of clothes and man in 'kebenek' is phrase to describe man who went on a dangerous mission, and phrase means that there is a hope that that man back alive from war. Thus words shroud and 'kebenek' are set as opposites and plays the role of contextual antonyms. Outside of the context these two words can neither be used as opposites nor compare as dead and alive.

From the concept life-death comes gradual pair dead-alive:

'But he, being the man who shed blood, knows how alive owe to the dead' (Zhumadilov 2004). We refer to it as gradual because there is an intermediate state between them (coma).

'We don't know whether Daryn alive or dead' (Akhmetzhan 2007).

Even if there is no special name for state between life and death, we can understand that there is in-between state from the context of the example:

"Either they felt the old woman's struggle who was between life and death, or were mad that owner didn't feed them on time, four dogs made a fuss by barking" (Akhmetzhan 2007).

Oppositions rich-poor, richness-poorness is an oppositional concept that appeared from the point of view of ethnolinguistic and cognitive theory of social inequality. A. Kaidar studied concept of 'wealth-poverty' from ethno-linguistic point of view, A.N.Samoilovich as oppositional concept, and V.Humboldt from point of notion. If A.N.Samoilovich divides the history of words 'wealth-poverty' into 4 periods, Z.T.Koshtanova states that time from the early XX century till this time is the fifth period of concept of 'wealth-poverty' (Koshanova 2009). In her work she takes the word 'wealth' as the core and shows words rich, 'bek', 'tore' as conceptual components of the core (Koshanova 2009).

Apart from that, this word has indirect (noble, livestock, prosperous) and associative words (sufficiency, food) as core layers. In Kazakh language it's noticeable that words opposite to wealth and rich, such as poverty, poor has additional emotional meanings of pity, compassion. If linguistic units that counted as part of this concept are gradual opposition in literal meaning, some of them are equipollent opposition. Examples of gradual opposition are:

Wealthy-less wealthy-unwealthy, propertied-deficit-indigent, many-few-none. Equipollent oppositions are the pairs: khan-slave, aristocrat-plebian, patrician-commoner, noble-lowly.

Z.T.Koshanova divides oppositional linguistic unit directly linked to the concept 'wealth-poverty' as: oppositional lexical unit: wideness-tightness, deficiency-sufficiency, hungry-full, strong-weak, pleasure-misery, thick-thin, freedomcaptivity, noble-ignoble and oppositional phraseological unit: beamed-suffered, rapacious-engorged (Koshanova 2009).

'One is wealthy, another is poor. Antipode of beggar is a rich man' (Zhumadilov 2004). 


\begin{abstract}
Human is tested by poverty,
And sometimes by wealth.

Poor and rich are not companions,

As well as not wolf and sheep.
\end{abstract}

\title{
3. Conclusion
}

In conclusion we have proved that because of usual antonymous oppositions, on which paremias are based, versatile for different languages (based on a single law of universal thought), they reflect a universal picture of the world. And contextual antonymous opposition expressed in tokens, indicating the specific national realities; so they reflect national language picture of the world. However, to clarify this statement further research is required on the material in different languages.

Each nation's stereotypical system based on national conscious builds linguistic image of the universe. Thus, antonymic oppositions plays an important role in formation of the most significant categories of existence, which creates a basis of universal and national picture of the world. For bulleted lists.

\section{References}

Akhmetbekov, K. (2010) Grief. Novel. Almaty: Zhalyn publishing house.

Ahmetzhan, T. (2008) Path of truth. Almaty: Zhalyn publishing house.

Ahmetzhan, T. (2007) Two-volume collection of works: Stories and plays. Almaty: Zhalyn publishing house.

Akberdieva, B. (2000) Mythological-perceptional structures in lexical-phraseological system. Almaty.

Akkozin, M. (1990) Kazakh proverbs and sayings. Almaty.

Akpanbet, A. (1994) Katyn kashkan: tales, fairy-tales, stories. Almaty: Zhalyn

Anikina, V. (1988) Russian proverbs and sayings. Moscow.

Bakbergenov, S. (2000) Blood on the snow. Novel. Astana: Elorda.

Batyr, D. (2008) Life passed without beloved: Novel, stories. Almaty: Kus zholy.

Ivanov,V. and Toporov V. (1965). Slavic linguistic modeling semiotic systems. Moscow.

Zhirenov S.A. XV-XIX perceptional nature of «Life - Death» concepts in poetry of poets and bards. PhD candidate of Philology dissertation - Almaty, 2007. - p.165

Kanapina, C. (2006) Cognoscibility image of proverbs and sayings in Kazakh language (on the basis of works of G.Mustafin and S.Mukanov). Almaty.

Kaupynbayev, T. (1986) Betegeli bel. Almaty: Zhazushy publishing house.

Koshanova, Z. (2009) Concept os 'wealth-poverty' in Kazakh language: cognoscibility description and function. Almaty.

Naimanbayev, K. (1991) Two-volume collection of works. vol. I novel, short stories. Almaty: Zhazushy publishing house.

Novikova, Y. (2010) Speech antonomy as reflection of ordinary picture of the world (on the material of American variation of English language). St.-Petersburg.

Permiakov, G. (1988) Basics of structural paremiology. Moscow.

Serikbayeva, U. (2005) Ethno-linguistic description of colors 'white' and 'black' in Kazakh language. Almaty.

Shalbayeva, A. (2010) Perceptional image of concepts goodness/evilness (on the basis of material in Kazakh and Russian languages). Almaty.

Zhumadilov, K. (2004) Only one life. Short stories. Almaty: Atamura.

Zhumadilov, K. (2003) Tweleve-volume collection of works. vol.I. Kokeikesti. Almaty: Kazigurt. 